\title{
Os biocombustíveis no Brasil: panorama atual, emissões gasosas e os métodos analíticos de monitoramento da qualidade do ar referente a gases de natureza orgânica
}

\author{
Biofuels in Brazil: the current scene, gaseous emissions and analytical \\ methods on air quality monitoring concerned to organic gases
}

\author{
Waldir Nagel Schirmer ${ }^{1 / *)}$ \\ Mayara Ananda Gauer ${ }^{2}$
}

Resumo

\begin{abstract}
A diminuição das reservas de petróleo, aliada às oscilações de seu preço e à pressão pela preservação do meio ambiente, evidenciam a necessidade de se diversificar a matriz energética mundial, por meio do uso de combustíveis renováveis. Grande parte da literatura referente a esse tema reporta, de fato, a redução significativa da grande maioria dos principais poluentes atmosféricos regulamentados. O presente trabalho aborda uma revisão do panorama dos biocombustíveis no Brasil (com ênfase no biodiesel), de modo sucinto, enfatizando os ganhos ambientais ao se substituir a matriz energética atual (predominantemente de origem fóssil), por combustíveis renováveis de origem vegetal. Traz ainda as principais técnicas de monitoramento no que se refere à amostragem e análise de gases orgânicos (especialmente compostos orgânicos voláteis), uma vez que compostos dessa natureza figuram entre os maiores poluentes do ar. Semelhantemente ao que se observa em âmbito internacional, a expectativa é de que, também no Brasil, ocorra um aumento no controle de fontes de poluentes dessa natureza, como a adoção de padrões de emissão mais rígidos (específicos para fontes de diferentes naturezas) e a inclusão de um programa de medida e controle/abatimento desses poluentes.
\end{abstract}

Palavras-chave: biocombustíveis; biodiesel; monitoramento ambiental; qualidade do ar.

I Dr.; Engenheiro Químico; Professor du curso de Engenharia Ambiental e professor do Programa de pósgraduação em Bioenergia da Universidade Estadual do Centro-Oeste, UNICENTRO; Bolsita de PósDoutorado Júnior do CNPq; Endereço: PR I53, km 7, CP: 2I, Riozinho, CEP 84500-000, Irati, Paraná, Brasil; E-mail:wanasch@hotmail.com (*) Autor para correspondência.

2 Engenheira Ambiental; Mestranda no Programa de Pós-Graduação em Bioenergia na Universidade Estadual do Centro-Oeste, UNICENTRO; Professora do Centro Universitário de União da Vitória, UNIUV, União da Vitória, Paraná, Brasil; E-mail: mayaragauer@yahoo.com.br

Recebido para publicação em 08/10/20II e aceito em 28/02/2012

\begin{tabular}{lllll}
\hline Ambiência Guarapuava (PR) v.8 n.I & P. I57- I75 Jan./Abr. 20I2 & ISSN I808 - 025I \\
DOI:10.5777/ambiencia.2012.01.0I rb & &
\end{tabular}


Abstract

The decrease of petroleum reserves, coupled with its price fluctuations and pressure for the preservation of the environment, highlight the need to diversify the global energy matrix, by means of the use of renewable fuels. The literature on this subject reports a significant reduction of the vast majority of major air pollutants regulated. This paper is a review of the scene of biofuels in Brazil (focusing on biodiesel), with emphasis in the environmental benefits by replacing the current energy matrix (mainly fossil fuels) by renewable sources with vegetable origin. It also brings the main techniques for monitoring in relation to sampling and analysis of organic gases (especially volatile organic compounds) in air, since such compounds are among the major air pollutants. Similarly to what is observed internationally, it is expected that, also in Brazil, there is an increase in the control of pollutants from sources such as the adoption of more stringent emission standards (specific sources of different natures) and the inclusion of a program of measurement and control / abatement of these pollutants.

Key words: air quality; biodiesel; biofuels; environmental monitoring.

\section{Introdução}

A deterioração da qualidade do ar, especialmente nos centros urbanos, tem despertado a atenção de cientistas para a importância das pesquisas relacionadas a esta temática, de modo a propor soluções e medidas mitigadoras para os impactos causados à atmosfera. A contribuição das emissões provenientes de fontes móveis (frota veicular) é hoje mais significativa do que aquela proveniente das atividades industriais (fontes fixas). Tal fato se deve ao aumento constante no número de veículos que circulam pelas ruas, especialmente nas grandes cidades, o que faz com que os padrões de emissão, regulamentados para alguns poluentes atmosféricos, sejam frequentemente excedidos. Conforme afirma Cunha (2008), o aumento da demanda pelo transporte de cargas e passageiros levou a um aumento direto da utilização de diesel como combustível, trazendo consequências desfavoráveis ao meio ambiente e contribuindo para a escassez de petróleo no planeta. Dessa maneira, de acordo com a mesma autora, a busca por fontes alternativas de energia que substituam os combustíveis fósseis e atendam aos requisitos econômicos, ambientais e sociais, é fator primordial no que se refere à manutenção do desenvolvimento sustentável.

No âmbito nacional, pesquisas abrangendo o desenvolvimento dos biocombustíveis como fonte energética vêm ganhando proporções cada vez maiores nos últimos anos. A grande maioria dessas pesquisas, entretanto, restringe-se apenas à investigação dos biocombustíveis como prováveis substitutos da gasolina e do diesel em termos de produção e equivalência energética, deixando de lado, muitas vezes, os aspectos ambientais relacionados ao seu uso. Os pouquíssimos estudos científicos que abordam investigações similares às propostas neste trabalho apontam vantagens no uso do biodiesel em relação ao diesel de petróleo (redução significativa dos principais gases poluentes). Outro aspecto favorável ao uso 
dos biocombustíveis refere-se à redução da emissão de gás carbônico, já que, durante a sua produção, há fixação de $\mathrm{CO}_{2}$ atmosférico no crescimento da biomassa, a qual será convertida em combustível.

O uso do biodiesel como fonte de energia surge como uma alternativa viável para substituir o óleo diesel em motores automotivos de combustão interna por compressão, pois, além de permitir a redução da dependência do setor de transportes em relação ao petróleo, pode ser considerado um combustível limpo e ecologicamente correto. Diante desse cenário, a presente revisão traz uma abordagem atual dos biocombustíveis no Brasil, com ênfase no biodiesel, destacando os ganhos ambientais decorrentes do seu uso no que se refere, principalmente, às emissões atmosféricas. Traz, ainda, as principais técnicas de monitoramento atmosférico no que se refere à amostragem e análise de gases de natureza orgânica (especialmente compostos orgânicos voláteis), uma vez que compostos dessa natureza figuram entre os maiores poluentes do ar (em termos de toxicidade e odor).

\section{A matriz energética brasileira e os biocombustíveis}

O petróleo e o carvão suprem, nos dias atuais, a maior parte das necessidades energéticas dos países industrializados. Tal fato serve como indicativo da quantidade de material fóssil manuseado e da magnitude dos problemas de poluição atmosférica relacionados à obtenção desses recursos, seu processo produtivo, transporte, refino, etc. (BOUBEL et al., 2004).

De acordo com Agência Nacional do Petróleo, Biocombustíveis e Gás Natural ANP (2010a), as reservas provadas mundiais de petróleo atingiram a marca de 1,3 trilhões de barris no ano de 2009, representando um crescimento de $0,1 \%$ em relação a 2008 . No que se refere às reservas provadas brasileiras, que correspondem a 12,9 bilhões de barris de petróleo, as mesmas tiveram um incremento de $0,4 \%$ e situaram o país na $16^{\mathrm{a}}$ posição no ranking mundial de reservas em 2009. Entre 2008 e 2009, a produção mundial de petróleo caiu de 82 para 79,9 milhões de barris por dia, evidenciando um decréscimo de 2,5\%. Ainda, em 2009, o consumo mundial de petróleo foi de 83,6 milhões de barris por dia, sendo que 1,9 milhão de barris por dia foi consumido no Brasil, o que representa 2,3\% do consumo mundial e coloca a nação na $11^{\mathrm{a}}$ posição entre os consumidores de petróleo. Considerando estes dados de reservas e consumo, pode-se estimar que o petróleo deve suprir a demanda mundial por aproximadamente 43 anos.Frente a esse aparente quadro de escassez, agravado pela dependência mundial de petróleo e gás provenientes de regiões do Oriente Médio, a busca por fontes alternativas de energia se torna imprescindível (BRASIL, 2006).

Nesse cenário de desenvolvimento e incentivo às fontes renováveis, o Brasil possui uma posição de destaque, especialmente no que se refere à bioenergia. Situado, predominantemente, nas faixas tropical e subtropical, o país possui excelentes condições para o desenvolvimento da agricultura energética, visto que recebe, durante todo o ano, intensa radiação solar. Além disso, suas grandes dimensões permitem a destinação de áreas exclusivas para a agricultura de energia, sem necessidade de reduzir a área destinada à produção alimentar, não levando à competição entre culturas energéticas versus culturas alimentares (BRASIL, 2006; QUINTELLA et al., 2009).

No âmbito nacional, pode-se dizer que o Brasil possui uma matriz energética 
limpa e diversificada, conforme pode-se observar na figura 1 , onde as fontes renováveis representam 45,4\%. Assim, em comparação aos países pertencentes à Organização para a Cooperação e Desenvolvimento Econômicos (OECD) e ao restante do mundo, a participação das fontes renováveis no Brasil é muito expressiva, correspondendo a quase metade de toda a energia ofertada no país. Tal fato denota que o país possui uma forte política e estratégia energética, que busca promover o fortalecimento das fontes alternativas de energia (RODRIGUES, 2006).

\section{Biomassa}

Conforme o Centro Nacional de Referência em Biomassa (CENBIO), a biomassa pode ser definida como "...todo recurso renovável oriundo de matéria orgânica (de origem animal ou vegetal) que pode ser utilizado para produção de energia" (http:// cenbio.iee.usp.br/saibamais/conceituando. $\mathrm{htm}$ ). Demirbas (2005) complementa este conceito afirmando que a biomassa ou energia solar armazenada sob a forma química nas plantas e nos animais é um dos mais importantes recursos renováveis existentes na terra. $\mathrm{O}$ mesmo autor considera como biomassa a celulose, a hemicelulose, a lignina, os lipídios, proteínas e açúcares, além da água, dos hidrocarbonetos e das cinzas.

Ainda, de acordo com o Banco Nacional de Desenvolvimento Econômico e Social (BNDES), o termo biomassa refere-se aos:

...recursos naturais que dispõem de bioenergia e que podem ser processados para fornecer formas bioenergéticas mais elaboradas e adequadas para o uso final. Portanto, seriam exemplos de fontes de bioenergia a lenha e os resíduos de serrarias, o carvão vegetal, o biogás resultante da decomposição anaeróbia de lixo orgânico e outros resíduos agropecuários, bem como os biocombustíveis líquidos, como o bioetanol e o biodiesel, e a bioeletricidade,

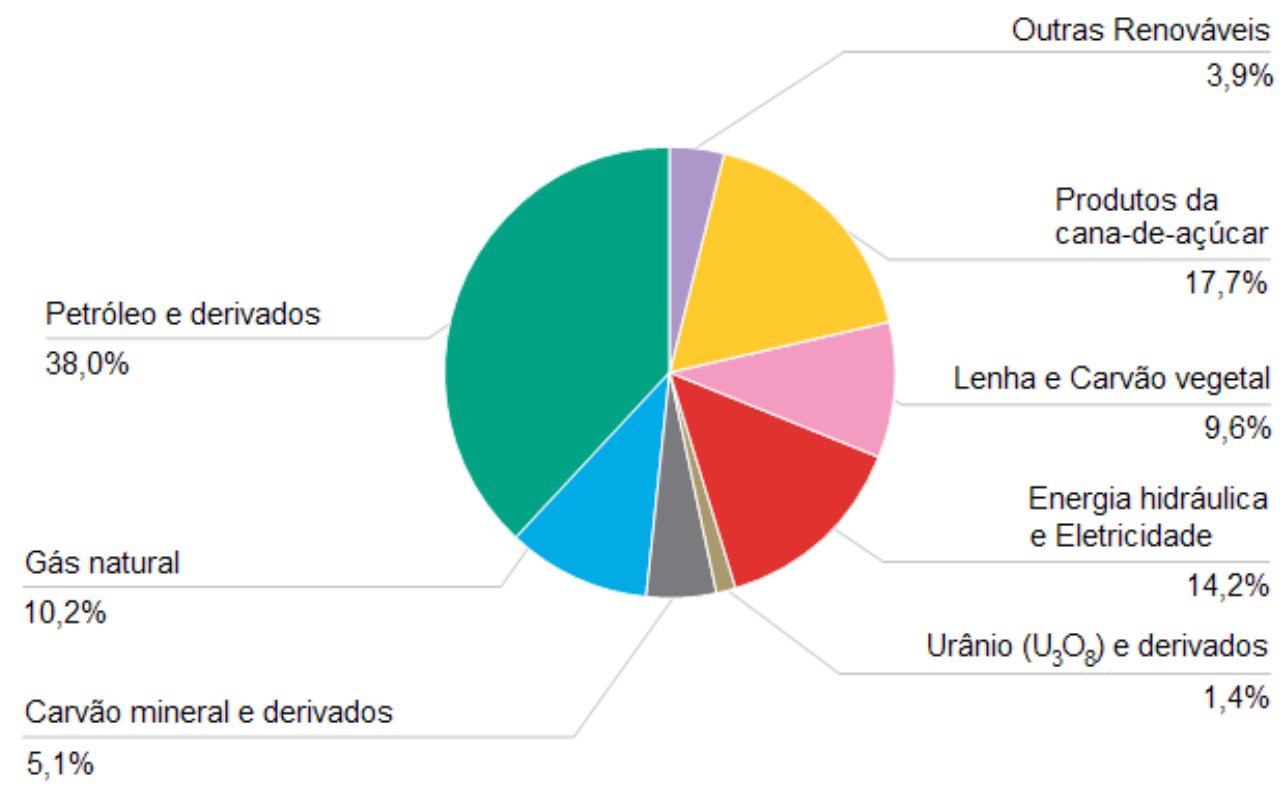

Figura I. Oferta interna de energia no Brasil no ano de 2010.

Fonte: Brasil (20 I la) 
gerada pela queima de combustíveis como o bagaço e a lenha (BNDES, 2008, p.25).

A utilização de biomassa como fonte energética não é algo recente. No período anterior à Revolução Industrial, a mesma era tida como um dos principais combustíveis disponíveis. Estima-se que no ano de 1850, a biomassa representava cerca de 85\% do consumo energético mundial, porém, com a intensificação do uso dos derivados de petróleo, no final do século XIX, esse percentual decresceu consideravelmente. Entretanto, no final do século XX, o uso da biomassa como combustível ressurgiu com bastante força e, segundo indicam algumas projeções, até o final do século XXI, a mesma representará de 10 a 20\% de toda a energia utilizada no planeta (GOLDENBERG, 2009). Já cenários mais otimistas indicam que, até 2050, o uso da biomassa moderna poderá representar de 10 a 50\% (DEMIRBAS et al., 2009).

Dentre as técnicas de conversão de biomassa em energia, merecem destaque, atualmente, a gaseificação, a co-geração, o uso do biogás produzido em aterros sanitários e os biocombustíveis (etanol e biodiesel) (GOLDEMBERG, 2009).

\section{Biocombustíveis}

Segundo a ANP, os biocombustíveis podem ser definidos como “...derivados de biomassa renovável que podem substituir, parcial ou totalmente, combustíveis derivados de petróleo e gás natural em motores à combustão ou em outro tipo de geração de energia" (ANP, 2010b, p. 211). Atualmente, dentre os biocombustíveis líquidos, destacamse, no Brasil, o etanol (proveniente da canade-açúcar) e o biodiesel (produzido a partir de óleos vegetais ou gorduras animais). Conforme dados da própria ANP, 18\% dos combustíveis consumidos dentro do país já são renováveis (ANP, 2010b), um percentual significativo e em expansão.

\section{Etanol}

O etanol é um combustível renovável que pode ser obtido a partir de diversas fontes vegetais, com destaque para a cana-de-açúcar (no Brasil, a cana é a única matéria-prima utilizada na produção de etanol) (ANP,2011a).

Oincentivoà produção e comercialização de etanol teve início a partir da década de 70 , com o surgimento do Programa Brasileiro do Álcool (Proálcool), criado com a estratégia de minimizar o consumo de combustíveis fósseis (especialmente gasolina), em virtude dos sucessivos aumentos nos preços do petróleo (ANP, 2011a).

Segundo a União da Indústria de Cana-de-açúcar (UNICA), a fabricação de motores, desenvolvidos especialmente para funcionar com etanol hidratado teve um grande crescimento a partir do surgimento do Proálcool sendo que, na década de 80 , os carros a etanol passaram a representar $84,4 \%$ da produção das montadoras instaladas no país. No entanto, a queda nos preços do petróleo, no fim dos anos 80, fez declinar significativamente a produção de etanol e, no fim da década de 90 , somente $1 \%$ da frota veicular vendida tinha motores próprios para uso do etanol (ANP, 2011a; UNICA, 2008).

A partir de 2003, com o lançamento dos veículos bicombustíveis, que podem ser abastecidos com álcool e gasolina e/ou suas misturas, a produção de etanol voltou a crescer. Em 2009, foram produzidos 26,1 milhões de metros cúbicos de etanol ${ }^{3}$, valor

3 Deste total, 7 milhões de metros cúbicos 
1,8 vezes maior que a produção no ano de 2003, o que evidencia a expansão e consolidação do setor sucroenergético (ANP,2010a).

\section{Biodiesel}

Quimicamente, define-se biodiesel como sendo o "combustível composto de alquil ésteres de ácidos graxos de cadeia longa, derivados de óleos vegetais ou de gorduras animais"(ANP, 2008, p.1).

No ano de 2004, o governo federal lançou o Programa Nacional de Produção e Uso de Biodiesel (PNPB), com o objetivo de implementar, de forma técnica e economicamente sustentável, a produção e uso do biodiesel, com enfoque na inclusão social e no desenvolvimento regional, via geração de renda e empregos (PORTAL DO BIODIESEL, 2010). Assim, a diversificação das fontes de energia, com o fortalecimento da participação das fontes renováveis, adquire caráter de política pública e estratégia energética, culminando com a promulgação da Lei $n^{\circ}$ 11.097, de 13 de janeiro de 2005, que dispõe sobre a introdução do biodiesel na matriz energética (BRASIL, 2005; RODRIGUES, 2006).

Segundo a Lei no 11.097, de 13 de janeiro de 2005, é considerado biodiesel todo "o biocombustível derivado de biomassa renovável para uso em motores a combustão interna ou, conforme regulamento, para outro tipo de geração de energia, que possa substituir parcial ou totalmente combustíveis de origem fóssil”.

correspondem à etanol anidro (etanol adicionado à gasolina $\mathrm{A}$ para formulação da gasolina C) e 19,1 milhões de metros cúbicos de etanol hidratado (para uso direto como combustível de automóveis).
A lei supracitada estabelece, ainda, o percentual mínimo obrigatório de adição de biodiesel ao diesel comercializado (5\% em volume), ao consumidor final, em todo território nacional. Para tanto, de acordo com o parágrafo primeiro desta mesma normativa, o prazo para aplicação dessa adição seria de oito anos, a contar da data de publicação da lei. No entanto, em virtude da grande produção e incentivos dados pelo governo, a exigência foi antecipada, passando a vigorar já em janeiro de 2010, conforme especifica a Resolução do Conselho Nacional de Política Energética (CNPE) no 6, de 2009 (BRASIL, 2005; BRASIL, 2009).

\section{As emissões de poluentes do diesel em comparação ao biodiesel}

Estima-se que, nos dias atuais, a frota veicular mundial seja dez vezes maior que a frota de cinquenta anos atrás. Devido a esse crescente aumento, os veículos automotores são considerados a principal fonte de poluição atmosférica urbana (FENGER, 2009).

De um modo geral, os veículos automotores podem emitir poluentes pelo seu escapamento (emissões diretas, ocorridas pela queima do combustível no motor) ou por meio de perdas evaporativas (evaporação de hidrocarbonetos do sistema de alimentação de combustível, ocasionada por mudanças de temperatura e pressão) que ocorrem durante o uso e/ou repouso do veículo. Tais emissões são influenciadas diretamente por fatores como porte, uso e idade do veículo, tecnologia do motor, manutenção e, principalmente, pelo tipo e qualidade do combustível utilizado (BRASIL, 2011b).

Os biocombustíveis, além de emitirem menos poluentes que os combustíveis fósseis durante sua queima, possuem seu 
processo de produção mais limpo, sendo considerados menos impactantes que os combustíveis tradicionais (ANP, 2010c). Além disso, os biocombustíveis (de modo geral) representam um atrativo sob o ponto de vista do aquecimento global. De forma simplificada, o ciclo de carbono dos vegetais consiste na fixação do carbono $\left(\mathrm{CO}_{2}\right)$ e liberação de oxigênio pelas plantas, por meio do processo de fotossíntese. Durante o processo de combustão, o oxigênio e o carbono combinam-se para gerar novamente $\mathrm{CO}_{2}$. É apropriado mencionar que o $\mathrm{CO}_{2}$ liberado pela combustão do diesel foi fixado a partir da atmosfera há milhões de anos. No entanto, o $\mathrm{CO}_{2}$ liberado na combustão do biodiesel tem fixação contínua pelas plantas e pode ser reciclado na próxima colheita. Assim, o tempo do ciclo de carbono para a fixação do $\mathrm{CO}_{2}$ e sua liberação a partir da combustão do biodiesel é muito menor (poucos anos), comparativamente ao tempo do ciclo do diesel. Essa vantagem constituise, inclusive, como base para elaboração de projetos de mecanismo de desenvolvimento limpo (MDL). Ainda, Nigam e Singh (2011) afirmam que o uso de biocombustíveis pode aumentar a segurança no abastecimento de combustível em muitos países e promover uma renda extra e estável para os agricultores.

Quando comparado aos combustíveis tradicionais (derivados de petróleo), o biodiesel é $100 \%$ renovável. Entretanto, quando se utiliza álcool metílico no processo de transesterificação do biodiesel, esta proporção cai para 90\% (para o balanço em massa), ou 95\% (para o balanço em massa de carbono), em virtude de esse tipo de álcool ter origem fóssil (BUYYUKAYA, 2010).

Em documento técnico publicado pela USEPA (2002), no qual se utilizou regressão estatística para correlacionar as emissões de poluentes regulamentados e não regulamentados do diesel e das misturas de biodiesel/diesel, concluiu-se que o uso do biodiesel apresenta vantagens ambientais. A Figura 2 apresenta os resultados obtidos em termos de emissões atmosféricas. Neste mesmo estudo [USEPA (2002)], estimou-se o impacto das emissões do uso da mistura contendo $20 \%$ de biodiesel de soja e $80 \%$ de diesel.Para esta situação, tem-se uma aumento de $2 \%$ nas emissões de $\mathrm{NO}_{x}$ e redução de $10,1 \%, 21,1 \%$ e $11,0 \%$ para o material particulado, hidrocarbonetos e monóxido de carbono, respectivamente.

Buyyukaya (2010) realizou testes com biodiesel de canola (B100), suas misturas com o diesel de petróleo (B5, B20 e B70) e diesel de petróleo puro (B0), em um motor diesel de seis cilindros, quatro-tempos e injeção direta acoplado a um dinamômetro hidráulico, com potência máxima de $350 \mathrm{~kW}$. Os testes foram feitos com o motor funcionando à plena carga, variando as rotações de 1000 a $2100 \mathrm{rpm}$, em intervalos de $200 \mathrm{rpm}$. O autor concluiu que o uso do biodiesel promove um aumento na formação de $\mathrm{NO}_{\mathrm{x}}$ e um menor retardamento de ignição, para todas as blendas testadas, incluindo biodiesel puro.

Ferreira et al. (2008) analisaram as emissões de compostos orgânicos voláteis $(\mathrm{COV})$ em motores de ignição por compressão abastecido com diesel e mistura de diesel e biodiesel (B10). No estudo, foi usado um motor com injeção indireta, quatro cilindros, acoplado a um dinamômetro hidráulico e potência máxima de $50 \mathrm{~kW}$. As condições de ensaio compreenderam o funcionamento do motor por 30 horas e posterior coleta de gases em sacos Tedlar, variando o torque em $36,1,45,2$ e $57,6 \mathrm{Nm}$ e mantendo a rotação constante em $2500 \mathrm{rpm}$. Os resultados evidenciaram uma redução na emissão de benzeno e etilbenzeno com a utili- 


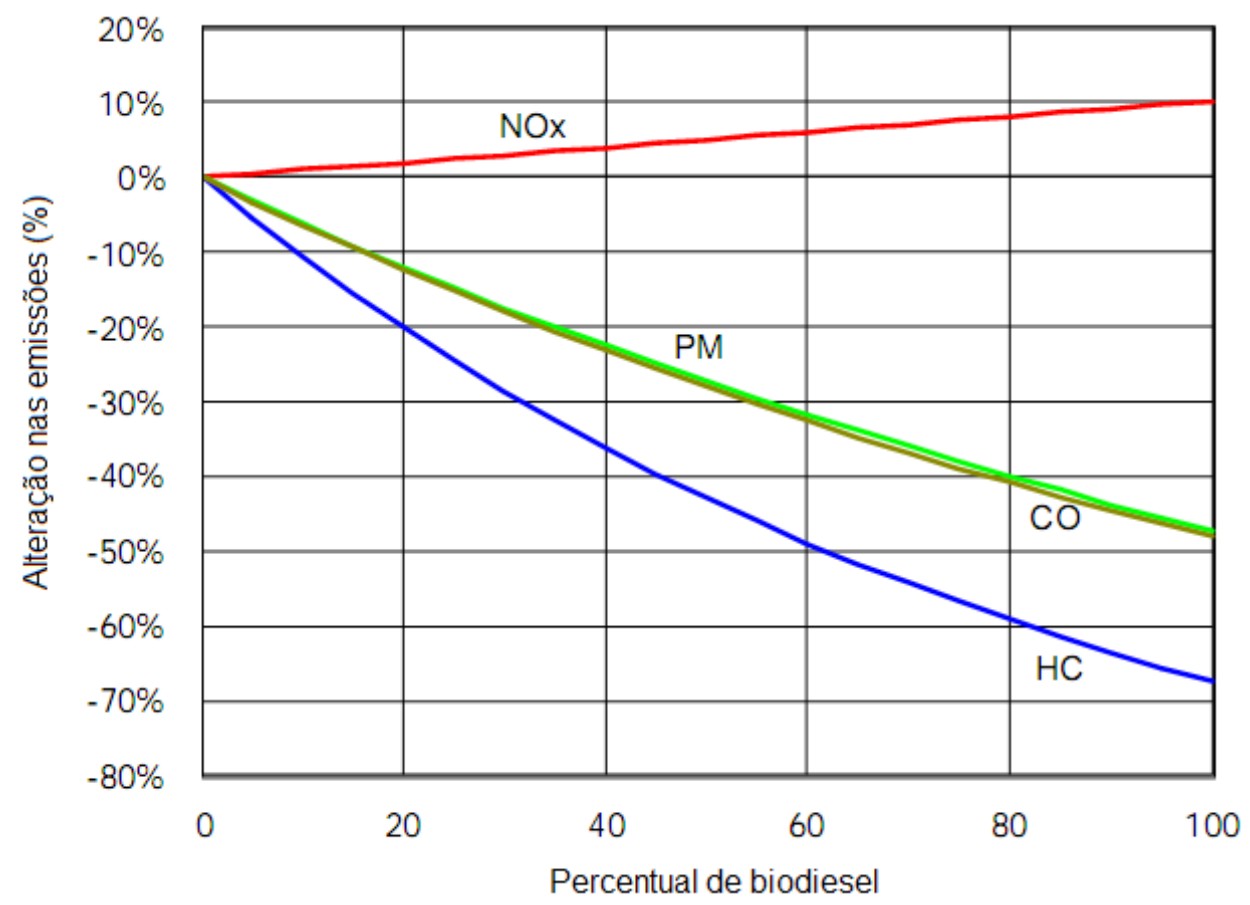

Figura 2. Impactos das emissões de biodiesel usado em veículos rodoviários pesados Fonte: USEPA (2002).

zação do B10, em comparação às emissões do diesel puro. Apesar disso, os autores destacaram que, conforme se aumentou a carga do motor (torque), as emissões de BTEX, tanto do diesel quando da blenda B10 aumentaram. Isso ocorre porque, ao se aumentar a carga de trabalho do motor, é necessária uma maior injeção de combustível, o que, consequentemente, leva a um aumento de emissões.

Miranda (2007) avaliou as diferenças existentes nas emissões atmosféricas provenientes da combustão, em motor monocilíndrico, do diesel, biodiesel de resíduos de óleos de fritura e suas misturas. Para os ensaios, a pressão de injeção do motor foi fixada em $125 \mathrm{kgf} / \mathrm{cm}^{2} \mathrm{e}$ a rotação em $1000 \mathrm{rpm}$. Os gases inorgânicos foram avaliados com analisadores automáticos enquanto os orgânicos foram coletados em sacos Tedlar, e posteriormente, analisados por cromatografia gasosa/espectrometria de massa. Os resultados obtidos demonstraram uma diminuição das concentrações de BTEX, CO e $\mathrm{SO}_{2}$ conforme se aumentou o teor de biodiesel no diesel. Já para os $\mathrm{NO}_{\mathrm{x}}$, evidenciou-se um aumento em suas concentrações à medida que se adicionou biodiesel ao diesel.

Corrêa e Arbilla (2006) testaram biodiesel etílico de mamona em um motor diesel de seis cilindros, injeção direta, sob rotação de 1500 rpm e em estado estacionário. Concluíram que os hidrocarbonetos monoaromáticos e poliaromáticos sofrem uma redução em suas emissões quando da adição de biodiesel ao diesel. 
Dorado et al. (2003) realizaram teste com biodiesel metílico de óleo de oliva residual e diesel puros em motor de injeção indireta operando em estado estacionário. Nesta situação, verificou-se que a utilização do biodiesel levou a uma redução nas emissões de $\mathrm{CO}$ (cerca de 59\%); $\mathrm{CO}_{2}$ (cerca de 9\%); $\mathrm{NO}$ (cerca de 37\%); e $\mathrm{SO}_{2}$ (cerca de 58\%). No entanto, o abastecimento do motor com este tipo de biodiesel promoveu um aumento de $81 \%$ nas emissões de $\mathrm{NO}_{2}$ e de $8,5 \%$ no consumo de combustível.

Castellanelli et al. (2008) usaram éster etílico de soja nas proporções de $0 \%$ (diesel puro), $2 \%, 5 \%, 10 \%, 20 \%, 50 \%, 75 \%$ e $100 \%$ em volume em motor diesel de injeção direta com quatro cilindros. Em relação ao desempenho do motor, os autores não encontraram diferenças entre o B0, B2, B5 e B10. No entanto, o emprego do B100 interferiu negativamente no quesito potência, torque e consumo específico, ao passo que a mistura $\mathrm{B} 20$ se mostrou como a mais eficiente em termos de desempenho, superando inclusive o diesel puro.

Volpato et al. (2009) utilizaram biodiesel de soja (B100) e diesel comercial em um motor de trator de $56 \mathrm{~kW}$ de potência, aspiração natural de 4 tempos, com sistema de injeção com bomba rotativa e acoplado à bancada dinamométrica, em seis níveis de rotação: 650, 570, 490, 410, 320 e $240 \mathrm{rpm}$. Para estas condições, os autores verificaram que o uso do biodiesel provocou uma perda de torque de 10,37\% em relação ao diesel, na rotação de trabalho $(540 \mathrm{rpm})$. Em relação à potência reduzida, constatou-se que, com o uso do combustível diesel, a mesma foi 6,1\% maior do que quando se usou biodiesel, na rotação de trabalho. No entanto, o biodiesel de soja apresentou um menor consumo específico e energético em relação ao diesel (14,66\% menor na rotação de trabalho de $540 \mathrm{rpm}$ ).
Corrêa et al. (2008) realizaram testes similares com biodiesel etílico de girassol nas misturas B5, B10, B20 e B100 e diesel puro. $\mathrm{O}$ uso das misturas B5, B10, B20 e B100 de ésteres alteraram o desempenho do motor, quando comparadas com o uso do diesel. No entanto, a redução máxima verificada da potência foi de $2,2 \%$ e o aumento máximo no consumo específico foi de 7,3\%, valores que, considerando todos os benefícios ambientais do biodiesel, são toleráveis.

Alguns estudos têm se preocupado também com as emissões de compostos oxigenados oriundos da queima do biodiesel em motores de combustão interna. A liberação desse tipo de substâncias para a atmosfera também gera certa preocupação sobre a comunidade científica, uma vez que muitos destes compostos, embora não regulamentados, podem exercer efeitos negativos sobre a saúde humana e o meio ambiente (formação de smog fotoquímico, por exemplo). No geral, o que se tem verificado é um aumento nas emissões de tais tipos de compostos conforme se aumenta o teor de biodiesel em diesel.

Corrêa e Arbilla (2008) verificaram as emissões de sete tipos de compostos oxigenados (formaldeído, acetaldeído, acroleína, acetona, propionaldeído, butiraldeído e benzaldeído) em motor diesel abastecido com diesel mineral e misturas de biodiesel $(2,5,10$ e $20 \%)$. Os testes procederam com o motor em estado estacionário, funcionando nas rotações de 1000,1500 e $2000 \mathrm{rpm}$. Os resultados obtidos demonstraram haver uma redução na emissão de benzaldeído para todas as blendas de biodiesel e um aumento (também para todas as blendas) nas emissões das demais carbonilas.

Outra classe de compostos com importância ambiental e de saúde pública são os hidrocarbonetos poliaromáticos (HPA). He et al. (2010), concluíram que o uso de 
biodiesel de soja, nas proporções 20\% e 100\%, em motor diesel com injeção indireta, reduziu as emissões de HPA em $13,1 \%$ e $19,4 \%$, respectivamente, quando comparados com o diesel de petróleo. Os autores verificaram ainda que houve uma redução significativa na emissão de HPA na fase particulada e que, na fase gasosa, predominaram as emissões de naftaleno e fenantreno.

Os trabalhos citados acima corroboram a afirmação de que as emissões do biodiesel são diretamente dependentes da matéria-prima precursora e das condições de operação do motor, como carga e potência. Entretanto, em qualquer caso, há um consenso de que o uso do biodiesel reduz a emissão da grande maioria dos poluentes atmosféricos regulamentados.

Monitoramento das emissões gasosas de natureza orgânica

\section{Amostragem de gases orgânicos}

A importância de se escolher técnicas confiáveis, sensíveis e exatas para o monitoramento das emissões gasosas (decorrentes do uso de combustíveis) justificase pela necessidade de se obterem informações seguras em relação aos componentes do ar, de modo que se possa controlar um problema ambiental. Assim, o método de amostragem escolhido deve ser o mais eficiente possível, já que problemas ocorridos nesta etapa podem levar a resultados sub ou superestimados e que não refletem as condições reais do meio (CRUZ; CAMPOS, 2008). A escolha de uma metodologia de amostragem e análise depende de fatores como a natureza dos poluentes a serem amostrados, condições do local de amostragem (quantidade de umidade, concentração dos poluentes) e tipo de dado requerido (amostragem instantânea, perfil contínuo, etc.) (GHELERI, 2003).

Os métodos de amostragem ativa e passiva, descritos a seguir, têm sido muito utilizados com a finalidade de investigar a qualidade do ar em centros urbanos e industriais, especialmente no que se refere ao monitoramento de compostos orgânicos voláteis - COV (RODRIGUES et al., 2007). A diferença básica entre a amostragem ativa e passiva é que, na primeira, o ar é succionado para o suporte absorvente ou adsorvente por uma bomba a vácuo, necessitando a utilização de dispositivos capazes de medir o fluxo de ar para que se determine a vazão de ar ou taxa de amostragem (CRUZ; CAMPOS, 2008).Já na segunda (amostragem passiva), predominam os fenômenos de difusão molecular, sendo que a transferência do gás para o suporte absorvente ou adsorvente é baseado na primeira Lei de Fick, a qual determina que o movimento de difusão das moléculas se dá pelas diferenças de concentração ao longo do volume do sistema (gradiente de concentração) (ANDRIETTA et al., 2010; GUARDANI e MARTINS, 2000).

\section{Amostragem ativa sem concentração}

A amostragem ativa sem concentração é uma técnica que pode ser empregada quando se tem, no ar, uma concentração elevada dos compostos que se deseja amostrar, o que permite sua caracterização (conforme os limites de detecção do equipamento) (SCHIRMER, 2004; UEDA, 2010). Nesta técnica (também conhecida como whole-air ou "coleta de amostra total"), o ar é coletado em recipientes fabricados a partir de ampolas (de vidro, metal), polímeros (sacos plásticos), ou aço inoxidável (contêineres metálicos), sendo estes dois últimos os mais utilizados 
(PARREIRA e CARDEAL, 2005; UEDA, 2010).

Os materiais usados na confecção dos sacos plásticos devem ser inertes (como Teflon, Tedlar, Mylar, Saran) para minimizar os efeitos de adsorção dos contaminantes sobre a superfície do saco e, consequentemente, perda de analito. Sugere-se que a análise do material coletado seja feita o mais rápido possível, pois os fenômenos de difusão e adsorção aumentam com o passar do tempo (ALTWICKER et al., 1999).

Os contêineres (também conhecidos como canisters) de aço inoxidável são recobertos com óxido de cromo-níquel e sílica fundida para "inertização" do material. Tal tratamento, aliado ao alto custo inicial dos canisters, inviabiliza, muitas vezes, a sua utilização, devido ao alto investimento para sua aquisição (UEDA, 2010).

\section{Amostragem ativa com concentração}

Em algumas situações, a concentração dos compostos no ar não é alta o suficiente para que seja detectada diretamente pelos equipamentos analíticos. Assim, quando o objetivo é a análise de componentes em nível de "traço",é necessário que se realize uma "préconcentração" das amostras, o que pode ser conseguido pelos processos de absorção (fase líquida), adsorção (fase sólida) ou por sistemas de criogenia. Neste caso, a amostra succionada passa por um processo de condensação e posterior congelamento no interior de um tubo vazio ou preenchido com material apropriado e imersão em fluido refrigerante (CRUZ e CAMPOS, 2008; PARREIRA e CARDEAL, 2005; SCHIRMER, 2004).

O processo mais comumente aplicado a gases orgânicos é o da adsorção. $\mathrm{O}$ fenômeno de adsorção baseia-se na capacidade que alguns sólidos porosos possuem de reter, seletivamente, alguns compostos químicos de interesse (SCHNELLE Jr; BROWN, 2002). Por esse motivo, adsorventes apropriados devem ser selecionados para cada espécie química que se deseja amostrar, para que a coleta e posterior dessorção para análise sejam asseguradas, sem nenhuma degradação da amostra. Os materiais com maiores chances de atender a estas exigências são aqueles que interagem com o analito por meio de forças de fraca intensidade (Forças de Van der Waals) (CICCIOLI et al, 2004; SOUSA, 2002).

Outras características desejáveis de um adsorvente são: a hidrofobicidade (de forma que o mesmo não retenha água e comprometa as etapas posteriores do monitoramento); o baixo custo; a facilidade de uso; a não geração de artefatos e volume de ruptura alto o suficiente para os compostos que se pretende amostrar (UEDA, 2010). Pode-se dizer também que um bom adsorvente é forte o bastante para reter os compostos de interesse e fraco o suficiente para possibilitar a dessorção térmica dos mesmos (WOOLFENDEN, 2010a).

Existe, disponíveis no mercado, uma grande variedade de sólidos adsorventes com aplicabilidade no monitoramento do ar. Nesse contexto, destacam-se os polímeros orgânicos porosos, os carvões grafitizados, as peneiras moleculares de carbono e o carvão vegetal ativado (RAS et al., 2009). A Tabela 1 apresenta os principais adsorventes usados na coleta de COV e algumas de suas propriedades.

Uma boa referência para a amostragem de gases utilizando-se de materiais adsorventes é o Método TO-17, da Agência de Proteção Ambiental dos Estados Unidos United States Enviromental Protection Agency 
(USEPA, 1999). Esse método estabalece todas as condições necessárias à coleta dos gases (essencialmente orgânicos) para posterior análise no sistema DTA-CG (dessorção térmica automática, cromatografia gasosa e detecção por espectrometria de massa ou ionização de chama), tais como melhor volume amostrado (de modo a evitar o ponto de ruptura do leito adsorvente), faixa de vazão, etc.

Outra questão bastante importante em relação à amostragem por adsorção é o controle da umidade. Muitas vezes, mesmo de gelo (SCHIRMER, 2004); purga a seco; membranas permeáveis; entre outros (WOOLFENDEN 2010a).

\section{Amostragem passiva}

Conforme mencionado anteriormente, a amostragem passiva é baseada no fluxo livre (difusão) das moléculas de analito presentes no ar até o meio de coleta. O método envolve, basicamente, o uso de tubos amostradores ou caixas (também conhecidas

Tabela I. Adsorventes comuns para coleta de COV no ar

\begin{tabular}{|c|c|c|c|c|c|}
\hline Adsorvente & $\underset{\left({ }^{\circ} \mathrm{C}\right)}{\text { T máx. }}$ & $\begin{array}{c}\text { Área } \\
\text { superficial } \\
\text { específica } \\
\left(\mathrm{m}^{2} \cdot \mathrm{g}^{-1}\right)\end{array}$ & Porosidade $^{(1)}$ & $\operatorname{Tipo}^{(2)}$ & $\begin{array}{l}\text { Hidrofo- } \\
\text { bicidade }^{(3)}\end{array}$ \\
\hline Carbopack C & $>400$ & 12 & MAP & NGC & $\mathrm{A}$ \\
\hline $\begin{array}{l}\text { Carbosieve S } \\
\text { III }\end{array}$ & 400 & 840 & MIP & PMC & B \\
\hline Carbotrap & $>400$ & 100 & MAP & $\mathrm{CBG}$ & A \\
\hline Carboxen 1000 & 400 & 1200 & MIP & PMC & B \\
\hline $\begin{array}{l}\text { Chromosorb } \\
106\end{array}$ & 20 & 750 & $\mathrm{P}$ & $\mathrm{SP}$ & A \\
\hline $\begin{array}{l}\text { Grânulos de } \\
\text { vidro (Glass } \\
\text { beads) }\end{array}$ & 400 & $<1$ & NP & Silicatos & A \\
\hline Porapak Q & 250 & 550 & $\mathrm{P}$ & EVB-DVB-CP & A \\
\hline Tenax GR & 350 & 35 & $\mathrm{P}$ & $\mathrm{PDPPO}+\mathrm{CBG}$ & A \\
\hline Tenax TA & 350 & 35 & $\mathrm{P}$ & PDPPO & $\mathrm{A}$ \\
\hline \multicolumn{6}{|c|}{$\begin{array}{l}\text { Nota: (1) MIP: microporos (diâmetro do poro de I a } 10 \mathrm{~nm} \text { ); P: poroso (diâmetro do poro de } 20 \text { a } 100 \quad \mathrm{~nm} \text { ); MAF } \\
\text { mesoporos ou macroporos (diâmetro do poro de } 100 \text { a } 300 \mathrm{~nm} \text { ); NP: não poroso. } \\
\text { (2) PMC:peneira molecular de carbono; EVB-DVB-CP: etilvinilbenzeno-divinilbenzeno-copolímero; CBG: carvão grafitizado } \\
\text { SP: poliestireno; PDPPO: poli (óxido de 2,6-difenil-p-fenileno). } \\
\text { (3) A: alta; B: baixa } \\
\text { Fonte:Adaptado de Ciccioli et al. (2004). }\end{array}$} \\
\hline
\end{tabular}

com a utilização de adsorventes hidrofóbicos, o vapor d'água pode interferir no sentido de danificar equipamentos e alterar os resultados das análises. Seu controle pode ser feito por meio de sais higroscópicos (como o carbonato de sódio, sulfato de magnésio, cloreto de cálcio) (GUILLOT et al., 2000); banho como badge). Em geral, os tubos amostradores possuem um longo caminho axial de difusão e pequena área transversal, o que resulta em taxas de amostragem relativamente baixas. Já em amostradores tipo caixas, os analitos percorrem um caminho mais curto de difusão e encontram uma maior área transversal, o que 
leva a maiores taxas de amostragem (KOTWASIK et al., 2007).

A amostragem passiva tem sido muito utilizada no monitoramento ambiental devido ao seu baixo custo, uma vez que não necessita de equipamentos elétricos e requer poucas análises durante o período de acompanhamento. Sua utilização é bastante indicada no caso de monitoramento ocupacional (exposição individual) e para avaliação da qualidade do ar em ambientes fechados. Ainda, pelo fato de ser um método pouco oneroso e de fácil operação, pode ser usado para monitorar diversos pontos simultaneamente, identificando possíveis fontes de emissão em determinada área, e ser utilizado em períodos de tempo relativamente longos. Tal fato, aliado à interpolação de resultados, permite a obtenção de mapas que descrevem a distribuição espacial da poluição (KOT-WASIK et al., 2007; KUME et al., 2008; VARDOULAKIS et al., 2009).

Dentre as limitações do método, as mais importantes estão relacionadas aos efeitos que as condições ambientais (temperatura e umidade do ar) podem exercer sobre os analitos. Entretanto, a amostragem passiva é uma alternativa promissora cujo potencial ainda não foi de todo explorado (KOT-WASIK et al., 2007).

\section{Análise de gases orgânicos}

De acordo com o Método TO-17, da USEPA (1999), que dispõe sobre as técnicas para amostragem e análise de COV, a técnica analítica mais adequada para quantificação e qualificação dos compostos é a cromatografia gasosa, acoplada a uma unidade de dessorção térmica e de um detector, que pode ser um espectrômetro de massas (EM) ou um detector de ionização de chama (DIC). Este último, segundo Skoog et al. (2005) é, em geral, um dos equipamentos mais empregados em aplicações envolvendo cromatografia gasosa.

Para fins de análise, é necessário que haja, inicialmente, a dessorção dos analitos retidos no tubo adsorvente. Assim, a recuperação da amostra é normalmente feita em equipamentos de dessorção térmica automática (ATD, do inglês "automatic thermal desorption"), ou por meio do uso de solventes (extração). Só então a amostra segue para a separação e detecção no sistema (GUILLOT et al., 2000; MIRANDA, 2007). $\mathrm{O}$ uso do ATD facilita significativamente a extração de gases orgânicos pré-concentrados em tubos adsorventes, levando a uma melhor concentração e transferência dos analitos dessorvidos para a coluna cromatográfica (WOOLFENDEN, 2010b).

O processo de separação cromatográfica se inicia com a introdução da amostra no injetor, onde a mesma é transferida (por meio do gás de arraste - fase móvel) através da coluna cromatográfica (fase estacionária). Os componentes da amostra são, então, eluídos e levados até o detector conectado ao final da coluna (PENTEADO et al., 2008).

Schirmer (2004) destaca que, quando se fala de cromatografia, um dos fatores definitivos para o sucesso da separação dos compostos é a escolha correta da coluna cromatográfica. Para COV, é difundido o uso de colunas capilares que variam de 0,23 a 0,53 mm de diâmetro e 25 a 100 m de comprimento. Ainda, a fase estacionária deve possuir características similares (compatibilidade) à natureza química dos compostos que se deseja analisar. A avaliação de substâncias mais polares deve prever o uso de colunas cromatográficas mais polares, ao passo que 
a avaliação de COV, por exemplo, exige o uso de colunas apolares ou com polaridade muito baixa (HELMIG, 1999; SANTOS e GALCERAN, 2002; SCHIRMER, 2004).

Ao contrário dos equipamentos de bancada (caso dos cromatógrafos), os analisadores automáticos compreendem equipamentos portáteis (também conhecidos como analisadores de campo) ou que podem ser instalados em algum local desejado para o monitoramento contínuo das emissões gasosas. Apesar da relativa simplicidade, a grande maioria desses tipos de analisadores possuem resolução de $1 \mathrm{ppm}$ e podem ser empregados para diversos tipos de gases (ALTWICKER et al., 1999). No caso de gases orgânicos, o princípio de detecção dos compostos é a ionização de chama (FID "flame ionization detector") (ÁLVARES JR.; et al., 2002).

\section{Conclusão}

A substituição dos combustíveis de petróleo pelos biocombustíveis é uma necessidade premente tanto nos países desenvolvidos quanto naqueles em desenvolvimento. A atual matriz energética, baseada, em sua maior parte, nos derivados fósseis, não apresenta sustentabilidade futura, em termos ambientais.

Dentro da classe dos combustíveis, aqueles de origem renovável (etanol e biodiesel) vêm ganhando importância crescente no cenário mundial, dados seus benefícios ambientais comprovados. A continuidade dos incentivos governamentais é fator essencial para a consolidação desses biocombustíveis no mercado e para que os mesmos possam competir, em termos econômicos, com os combustíveis tradicionalmente usados.
Os dados disponíveis na literatura confirmam as vantagens ambientais oriundas da utilização do biodiesel em motores de compressão interna. A grande maioria dos gases poluentes (exceção para os NOx) e potencialmente prejudiciais à saúde humana tem suas emissões reduzidas quando da combustão deste produto energético. Assim, sob o ponto de vista ambiental, a adição de percentuais cada vez maiores de biodiesel ao diesel, é um fator muito interessante, tendo em vista as comprovações científicas disponíveis.

Num cenário de crescente degradação da qualidade do ar nos grandes centros urbanos, o monitoramento das espécies químicas presentes na atmosfera é essencial para a tomada de decisão por parte dos órgãos responsáveis. O aumento progressivo da frota veicular é um fator que exige atenção, pois a poluição gerada pelas fontes móveis, além de ser de difícil controle, vem apresentando uma tendência a aumentar cada vez mais.

Diante do exposto, o uso de combustíveis alternativos se faz necessário tanto por medidas de segurança energética (em virtude das constantes crises do setor petrolífero), quanto pelas questões ambientais e de saúde pública. A diminuição da emissão de gases que causam efeito estufa, chuva ácida e smog fotoquímico pode ser conseguida com sucesso por meio da substituição do diesel pelo biodiesel, o que, por si só, já representa um grande avanço em termos de controle da poluição atmosférica.

\section{Agradecimentos}

Os autores agradecem ao Conselho Nacional de Desenvolvimento Científico e Tecnológico $(\mathrm{CNPq})$ pelo apoio financeiro ao projeto. 


\section{Referências}

AGÊNCIA NACIONAL DO PETRÓLEO, BIOCOMBUSTÍVEIS E GÁS NATURAL - ANP. Resolução n ${ }^{\circ}$ 07, de 19 de março de 2008. Dispõe sobre a especificação do biodiesel a ser comercializado pelos diversos agentes econômicos autorizados em todo o território nacional. Diário Oficial [da] República Federativa do Brasil, ANP, Brasília, DF, 20 mar. 2008.

AGÊNCIA NACIONAL DO PETRÓLEO, BIOCOMBUSTÍVEIS E GÁS NATURAL - ANP. Anuário Estatístico Brasileiro do Petróleo, Gás Natural e Biocombustíveis. Rio de Janeiro: ANP, 2010a. 227 p.

AGÊNCIA NACIONAL DO PETRÓLEO, GÁS NATURAL E BIOCOMBUSTÍVEIS - ANP. Biocombustíveis. 2010b. Disponível em: < http://www.anp.gov.br/?pg=33972\&m=\& $\mathrm{t} 1=\& \mathrm{t} 2=\& \mathrm{t} 3=\& \mathrm{tt} 4=\& a r=\& p s=\& c a c h e b u s t=1298377581721>$. Acesso em: 14 jan. 2011.

AGÊNCIA NACIONAL DO PETRÓLEO, GÁS NATURAL E BIOCOMBUSTÍVEIS - ANP. Biocombustíveis. 2010c. 2 p. Disponível em: $<$ http://www.anp.gov.br/?id=470 $>$. Acesso em: 22 set. 2011.

AGÊNCIA NACIONAL DO PETRÓLEO, GÁS NATURAL E BIOCOMBUSTÍVEIS - ANP. O etanol combustível. 2011a. Disponível em: < http://www.anp.gov.br/?pg=40786\& $\mathrm{m}=\& \mathrm{t} 1=\& \mathrm{t} 2=\& \mathrm{t} 3=\& \mathrm{t} 4=\& a r=\& p s=\& c a c h e b u s t=1300801545403>$. Acesso em: 21 mar. 2011 .

ALTWICKER, E. R.; CANTER, L. W.; CHA, S. S.; CHUANG, K. T.; LIU, D. H. F.; RAMACHANDRAN, G.; RAUFER, R. K.; REIST, P. C.; SANGER, A. L. R.; TURK, A.; WAGNER, C.P.(Ed.). Air Pollution. In: ALLER, M.Environmental Engineer's Handbook. Boca Raton, Florida: CRC Press LLC, 1999.

ÁLVARES JR, O. M.; LACAVA, C. I. V.; FERNANDES, P. S. Emissões Atmosféricas. Brasília: SENAI/DN, 2002.373 p.

ANDRIETTA, L. C. G.; TOMAZ, E.; TRESMONDI, A. C. C. L.; CREMASCO, M. A. Experimental determination of benzene uptake rate in Tenax TA diffusive samplers. Química Nova, São Paulo, v. 33, n. 5, p. 1034-1038, 2010.

BANCO NACIONAL DE DESENVOLVIMENTO ECONÔMICO E SOCIAL - BNDES (Coord.). Bioetanol de cana-de-açuçar - Energia para o desenvolvimento sustentável. Rio de Janeiro: BNDES, 2008. 316 p.

BOUBEL, R. W.; FOX, D. L.; TURNER, D. B.; STERN, A. C. Fundamentals of Air Pollution. 3. ed. San Diego, California: Academic Press, 1994.

BRASIL. Ministério de Minas e Energia. Conselho Nacional de Política Energética. Resolução $\mathrm{n}^{\mathrm{o}}$ 06, de 16 de setembro de 2009. Estabelece em cinco por cento, em volume, o percentual mínimo obrigatório de adição de biodiesel ao óleo diesel comercializado ao consumidor final, 
de acordo com o disposto no art. $2^{\circ}$ da Lei no 11.097, de 13 de janeiro de 2005. Diário Oficial [da] República Federativa do Brasil, CNPE, Brasília, DF, 26 out. 2009.

BRASIL. Ministério da Agricultura, Pecuária e Abastecimento. Plano Nacional de Agroenergia 2006-2011. 2 ed. Brasília: Embrapa Informação Tecnológica, 2006. 110 p.

BRASIL. Ministério de Minas e Energia. Empresa de Pesquisa Energética - EPE. Balanço Energético Nacional 2011 - Ano base 2010: Resultados Preliminares. Rio de Janeiro: EPE, 2011a. 49 p.

BRASIL. Ministério do Meio Ambiente. Secretaria de Mudanças Climáticas e Qualidade Ambiental. $1^{\circ}$ Inventário Nacional de Emissões Atmosféricas por Veículos Automotores Rodoviários. Brasília, Departamento de Mudanças Climáticas, Gerência de Qualidade do Ar, 2011b. 114 p.

BUYUKKAYA, E. Effects of biodiesel on a DI diesel engine performance, emission and combustion characteristics. Fuel, v. 89, n.10, p. 3099-3105, 2010.

CASTELLANELLI,M.; DE SOUZA, S.N.M.; SILVA, S. L.; KAILER, E. K. Desempenho de motor ciclo diesel em bancada dinamométrica utilizando misturas diesel/biodiesel. Engenharia Agrícola, Jaboticabal, v. 28, n. 1, p. 145-153, 2008.

CENTRO NACIONAL DE REFERÊNCIA EM BIOMASSA - CENBIO. Conceituando biomassa. Disponível em: <http://cenbio.iee.usp.br/saibamais/conceituando.htm>.Acesso em: 25 jul. 2011.

CICCIOLI, P.; BRANCALEONI, E.; FRATTONI, M.; MARIS, C. Sampling of atmospheric volatile organic compounds (VOCS) with sorbent tubes and their analysis by GC-MS. In: Environmental Monitoring Handbook. McGraw-Hill: Digital Engineering Library, 2004.

CORREAA, S. M.; ARBILLA, G. Carbonyl emissions in diesel and biodiesel exhaust. Atmospheric Environment, v. 42, n.4, p. 769-775, 2008.

CORREAA, S. M.; ARBILLA, G. Aromatic Hydrocarbons emissions in diesel and biodiesel exhaust. Atmospheric Environment, v. 40, n.35, p. 6821-6826, 2006.

CORRÊA, I. M.; MAZIERO, J. V. G.; ÚNGARO, M. R.; BERNARDI, J. A.; STORINO, M. Desempenho de motor diesel com misturas de biodiesel de óleo de girassol. Ciência e Agrotecnologia, Lavras, v. 32, n. 3, p. 923-928, 2008.

CRUZ, L.P.S.; CAMPOS, V.P. Métodos de amostragem e análise para compostos reduzidos de enxofre atmosférico. Química Nova, São Paulo, v. 21, n. 5, p. 1180-1189, 2008.

CUNHA, M. E. Caracterização de Biodiesel Produzido com Misturas Binárias de Sebo Bovino, Óleo de Frango e Óleo de Soja. 2008. 86f. Dissertação (Mestrado em Química) Instituto de Química, Universidade Federal do Rio Grande do Sul, Porto Alegre, 2008. 
DEMIRBAS, A. Potential applications of renewable energy sources, biomass combustion problems in boyler power systems and combustion related environmental issues. Progress in Energy and Combustion Science, v. 31, n.2, p. 171-192, 2005.

DEMIRBAS, M. F.; BALAT, M.; BALAT, H. Potential contribution of biomass to the susteinable energy development. Energy Conversion and Management, v. 50, n.7, p. 1746$1760,2009$.

DORADO, M.P.; BALLESTEROS, E.; ARNAL,J.M.; GÓMEZ,J.; LÓPEZ,F.J. Exhaust emissions from a Diesel engine fueled with transesterified waste olive fuel. Fuel, v. 82, n.11, p. 1311-1315, 2003.

FENGER,J.Air pollution in the last 50 year - from local to global.Atmospheric Environment, v. 43, n.1, p. 13-22, 2009.

FERREIRA, S. L.; SANTOS, A. M.; SOUZA, G. R.; POLITO, W. L. Analysis of the emissions of volatile organic compounds from the compression ignition engine fueled by dieselbiodiesel blend and diesel oil using gas chromatography. Energy, v. 33, n.12, p. 1801-1806, 2008.

GOLDEMBERG,J.Biomassa e energia. Química Nova, São Paulo, v. 32, n. 3, p. 582-587, 2009.

GUARDANI, M. L. G.; MARTINS, M. H. R. B. Monitor passivo de dióxido de enxofre - construção e testes de validação. In: CONGRESSO INTERAMERICANO DE ENGENHARIA SANITÁRIA E AMBIENTAL, 27., 2000, Porto Alegre, Anais... Porto Alegre, ABES, 2000. p.1-9.

GHELERI, L. C. Amostragem passiva de benzene presente na atmosfera. 2003. $142 \mathrm{f}$. Dissertação (Mestrado em Engenharia Química) - Universidade Estadual de Campinas, Campinas, 2003.

GUILLOT,J.M.; FERNANDEZ, B.; LE CLOIREC,P.Advantages and limits of adsorption sampling for physic-chemical measurements of odorous compounds. Analysis, v. 28, n. 3, p. 180-187, 2000.

HE, C.; GE, Y.; TAN, J.; YOU, K.; HAN, X.; WANG, J. Characteristics of polycyclic aromatic hydrocarbons emission of diesel engine fueled with biodiesel and diesel. Fuel, v. 89, p. 2040-2046, 2010.

HELMIG, D. Air analysis by gas chromatography. Journal of Chromatography A, v. 843, p. 129-146, 1999.

KOT-WASIK, A.; ZABIEGALA,B.;URBANOWICZ,M.; DOMINIAK, E.;WASIK,A.; NAMIESNIK,J.Advances in passive sampling in environmental studies. Analytica Chimica Acta, v. 602, p. 141-163, 2007. 
KUME, K.; OHURA, T.; AMAGAI, T.; FUSAYA, M. Field monitoring of volatile organic compounds using passive air samplers in a industrial city in Japan. Environmental Pollution, v. 153 , p. 649-657, 2008.

MIRANDA, G. R. Avaliação das Emissões Atmosféricas Provenientes da Combustão do Diesel, Biodiesel de Óleo de Fritura e suas Misturas. 2007. 108f. Dissertação (Mestrado em Engenharia Ambiental) - Universidade Federal de Santa Catarina, Florianópolis, 2007.

NIGAM, P. A.; SINGH, A. Production of liquid biofuels from renewable sources. Progress in Energy and Combustion Science, v. 37, p. 52-68, 2011.

PARREIRA, F.V.; CARDEAL, Z. L. Amostragem de compostos orgânicos voláteis no ar utilizando a técnica de microextração em fase sólida. Química Nova, São Paulo, v. 28, n. 4, p. 646-654, 2005).

PENTEADO, J. C. P.; MAGALHÃES, D.; MASINI, J. C. Experimento didático sobre cromatografia gasosa: uma abordagem analítica e ambiental. Química Nova, São Paulo, v. 31, n. 8, p. 2190-2193, 2008.

PORTAL DO BIODIESEL.Programa Nacional de Produção e Uso do Biodiesel. Disponível em: < http://www.biodiesel.gov.br/>. Acesso em: 4 dez. 2010.

QUINTELLA, C. M.; TEIXEIRA, L. S. G.; KORN, M. G. A.; COSTA NETO, P. R.; TORRES, E. A.; CASTRO, M. P.;JESUS, C. A. C. Cadeia do biodiesel da bancada à indústria: uma visão geral com prospecção de tarefas e oportunidades para P\&D\&I. Química Nova, São Paulo, v. 32, n. 3, p. 793-808, 2009.

RAS, M. R.; BORRULL, F.; MARCÉ, R.M. Sampling and preconcentration techniques for determination of volatile organic compounds in air samples. Trends in Analytical Chemistry, v. 28, n. 3, 2009.

RODRIGUES, D. G.; TRESMONDI, A. C. C. L; ALBUQUERQUE, E. L.; TOMAZ, E. Avaliação das Concentrações de Compostos Orgânicos Voláteis no Município de Espírito Santo do Pinhal - SP Através de Amostragem Passiva - Parte I. Engenharia Ambiental, Espírito Santo do Pinhal, v.4, n.2, p. 38-51, 2007.

RODRIGUES, R. A. Biodiesel no Brasil: Diversificação Energética e Inclusão Social com Sustentabilidade.In: FERREIRA,J. R.; CRISTO, C.M.P.N.(Coord.). O futuro da Indústria Biodiesel: Coletânea de artigos. Brasilia: MDIC-STI/IEL, 2006. 145 p.

SANTOS, F.J.; GALCERAN, M.T.The application of gas chromatography to environmental analysis. Trends in analytical chemistry, v. 21, n. 9 e 10, p. 672-685, 2002.

SCHIRMER, W. N. Amostragem, análise e proposta de tratamento de compostos orgânicos voláteis (COV) e odorantes em estação de despejos industriais de refinaria de petróleo. 2004. 140f. Dissertação (Mestrado em Engenharia Ambiental) - Universidade Federal de Santa Catarina, Florianópolis, 2004. 
SCHNELLEJÚNIOR, K. B.; BROWN, C. A. Air Pollution Control Technology Handbook. Boca Raton: CRC Press LLC, 2002.

SKOOG, D. A.; WEST,D.M.; HOLLER, F.J.; CROUCH, S. R. Fundamentos de Química Analítica. 8. ed. Cengage Learning, 2005. 1024p.

SOUSA, K. R. P. Estudos sobre Compostos Orgânicos Voláteis Presentes no Ar do Município de Paulínia. 2002. 221f. Dissertação (Mestrado em Engenharia Química) Universidade Estadual de Campinas, Faculdade de Engenharia Química, Campinas, 2002.

UNITED STATES ENVIRONMENTAL PROTECTION AGENCY (USEPA). Compendium of Methods for the Determination of Toxic Organic Compounds in Ambient Air. Compendium Method TO-17 - Determination of Volatile Organic Compounds in Ambient Air Using Active Sampling Onto Sorbent Tubes. 1999. EPA/625/R-96/010b. 53 p.

UNITED STATES ENVIRONMENTAL PROTECTION AGENCY (USEPA). A Comprehensive Analysis of Biodiesel Impacts on Exhaust Emissions - Draft Technical Report. 2002. EPA-420-P-02-001.126p.

UEDA, A. C. Estudo de compostos orgânicos voláteis na atmosfera da região metropolitana de Campinas. 2010.282f. Tese (Doutorado em Engenharia Química) - Universidade Estadual de Campinas, Campinas, 2010.

UNIÃO DAS INDÚSTRIAS DE CANA DE AÇUCAR (UNICA). Setor sucroenergético. 2008. Disponível em: <http://www.unica.com.br/content/show.asp?cntCode=11891360-41CC459C-9A22-191506941834>. Acesso em: 25 jul. 2011.

VARDOULAKIS, S.; LUMBRERAS,J.; SOLAZZO, E. Comparative evaluation of nitrogen oxides ando zone passive diffusion tubes for exposure studies. Atmospheric Environment, v. 43, p. 2509-2517, 2009.

VOLPATO, C. E. S.; CONDE, A.P.; BARBOSA, J. A.; SALVADOR, N. Desempenho de motor diesel de quatro tempos alimentado com biodiesel de óleo de soja (B100). Ciência e Agrotecnologia, v. 33, n. 4, p. 1125-1130, 2009.

WOOLFENDEN, E. Sorbent-based sampling methods for volatile and semi-volatile organic compounds in air - Part 2: Sorbent selection and other aspects of optimizing air monitoring methods. Journal of Chromatography A, v. 1217, p. 2685-2694, 2010a.

WOOLFENDEN, E. Sorbent-based sampling methods for volatile and semi-volatile organic compounds in air-Part 1: Sorbent-based air monitoring options. Journal of Chromatography A, v. 1217, p. 2674-2684, 2010b. 